\title{
Resolution of cryptosporidiosis with probiotic treatment
}

\author{
N Pickerd, D Tuthill
}

Postgrad Med J 2004;80:112-113. doi: 10.1136/pmj.2003.014175

Cryptosporidium infection is usually self limited, but can be a life threatening illness in immunocompromised patients. Probiotics have been used successfully in the treatment of acute diarrhoea and they have also been shown to limit Cryptosporidium parvum infection in animal models. The first case of successful resolution of prolonged cryptosporidiosis with probiotic treatment is reported.

C ryptosporidium infection usually causes a self limited diarrhoeal illness lasting between two and four weeks patients.

Other than rehydration and correction of electrolyte abnormalities, definitive therapy has not been established. Paromomycin, azithromycin, or nitazoxanide may be beneficial for some patients and in immunocompromised patients orally administered human serum immunoglobulin has been beneficial. ${ }^{1}$ Probiotics have been used successfully in the treatment of acute diarrhoea ${ }^{2}$ and also in preventing antibiotic induced diarrhoea. ${ }^{3}$ They have also been shown to limit Cryptosporidium parvum infection in immunocompromised individuals in animal models. ${ }^{4-6}$

We report the first case of successful resolution of prolonged cryptosporidiosis with probiotic treatment.

\section{CASE REPORT}

A 12 year old girl of previous good health had been diagnosed with coeliac disease at 9 years of age after an 18 month history of vomiting, loose stools, and mouth ulcers. At diagnosis she had positive antigliadin and antiendomysial antibodies with a normal IgA level and a positive small bowel biopsy. On a gluten-free diet she was completely asymptomatic for 25 months.

At 12 years and 2 months of age she presented with a four month history of abdominal pain, flatulence, loose stools, nausea, and lethargy. Her abdominal pain had been severe enough to stop her school attendance for the preceding two months. Her growth had been maintained along the 25th centile and apart from slight epigastric tenderness her examination was entirely normal.

Laboratory data revealed a normal full blood count and erythrocyte sedimentation rate, negative Helicobacter pylori serology, and normal antitissue-transglutaminase levels. An initial stool sample sent from the general practitioner after a month of symptoms was negative for cryptosporidium. A further stool sample sent four months into her diarrhoeal illness revealed cryptosporidium oocysts but no other pathogens.

In view of the benefits of probiotics in infectious diarrhoea she was started on a four week course of Lactobacillus GG $10^{9}$ units/day (Culturelle, CAG Functional Foods, Omaha, USA) and Lactobacillus casei Shirota $6.5 \times 10^{9}$ units/day (Yakult UK Ltd, London, UK) treatment. Within 10 days of starting treatment her nausea and diarrhoea had completely resolved and her abdominal pain markedly reduced, enabling her to return to school.

A repeat stool sample four weeks after starting treatment with probiotics was clear of cryptosporidium oocysts.

\section{DISCUSSION}

The most fully documented beneficial effect of probiotic intervention is the treatment of acute infectious diarrhoea. Well controlled clinical studies have shown that probiotics such as Lactobacillus rhamnosus $G G, L$ reuteri, $L$ casei Shirota, and Bifidobacterium lactis can shorten the duration of acute rotavirus diarrhoea. ${ }^{78}$ Research in immunodeficient mice has also suggested that treatment with probiotics can reduce the parasite burden in the intestinal epithelium during cryptosporidiosis..$^{4-6}$

The natural course of cryptosporidiosis is to resolve over two to four weeks in immunocompetent patients. Our patient had no other signs or symptoms of immunodeficiency and a normal serum IgA level. We are unaware of any research to suggest altered susceptibility to cryptosporidiosis in persons with coeliac disease.

Despite the longevity of her symptoms (four months), within 10 days of starting treatment with probiotics her persistent diarrhoea, abdominal pain, and school absence resolved.

The initial stool sample sent at the onset of symptoms was probably falsely negative due to either intermittent shedding of oocysts or failure of the routine laboratory examination to detect the oocysts. ${ }^{1}$

We believe this is the first case where probiotics have been successfully used to treat cryptosporidiosis in humans resulting in a prompt clinical improvement and resolution of infection. This benign treatment holds therapeutic promise.

\section{Authors' affiliations \\ N Pickerd, D Tuthill, Department of Paediatrics, Llandough Hospital, Cardiff, UK}

Correspondence to: $\operatorname{Dr} \mathrm{N}$ Pickerd, Department of Paediatrics, Llandough Hospital, Penlan Road, Cardiff CF64 2XX, UK; nicolepickerd@yahoo.com

Submitted 29 August 2003

Accepted 1 September 2003

\section{REFERENCES}

1 American Academy of Pediatrics. Red book. Report of the Committee on Infectious Diseases. 25th Ed. Elk Grove Village, IL: AAP, 2000:224.

2 Saavedra J. Probiotics and infectious diarrhea. Am J Gastroenterol 2000;95(suppl):16-18.

3 D'Souza AL, Rajkumar C, Cooke J, et al. Probiotics in prevention of antibiotic associated diarrhoea: meta-analysis. BMJ 2002;324:1361-4.

4 Alak JIB, Wolf BW, Mdurvwa EG, et al. Effect of Lactobacillus reuteri on intestinal resistance to Cryptosporidium parvum infection in a murine model of aquired immunodeficiency syndrome. J Infect Dis 1997;175:218-21. 
5 Waters WA, Harp JA, Wannemuehler MJ, et al. Effects of Lactobacillus reuteri on Cryptosporidium parvum infection of gnotobiotic TCR- $\alpha$-deficient mice. $J$ Eukaryot Microbiol 1999;46:60-1.

6 Alak JI, Wolf BW, Mdurvwa EG, et al. Supplementation with Lactobacillus reuteri or $L$ acidophilus reduced intestinal shedding of cryptosporidium parvum oocysts in immunodeficient C57BL/6 mice. Cell Mol Biol 1999;45:855-63.
7 Szajewska H, Mrukowicz JZ. Probiotics in the treatment and prevention of acute infectious diarrhea in infants and children: a systematic review of published randomized, double-blind, placebo-controlled trials. J Pediatr Gastroenterol Nutr 2001;33:17-25.

8 Guandalini S, Pensabene L, Zikri MA. Lactobacillus GG administered in ora rehydration solution to children with acute diarrhea: a multicenter European trial. J Pediatr Gastroenterol Nutr 2000;30:54-60.

\section{Clinical Evidence-Call for contributors}

Clinical Evidence is a regularly updated evidence based journal available worldwide both as a paper version and on the internet. Clinical Evidence needs to recruit a number of new contributors. Contributors are health care professionals or epidemiologists with experience in evidence based medicine and the ability to write in a concise and structured way.

\section{Currently, we are interested in finding contributors with an interest in} the following clinical areas:

Altitude sickness; Autism; Basal cell carcinoma; Breast feeding; Carbon monoxide poisoning; Cervical cancer; Cystic fibrosis; Ectopic pregnancy; Grief/bereavement; Halitosis; Hodgkins disease; Infectious mononucleosis (glandular fever); Kidney stones; Malignant melanoma (metastatic); Mesothelioma; Myeloma; Ovarian cyst; Pancreatitis (acute); Pancreatitis (chronic); Polymyalgia rheumatica; Post-partum haemorrhage; Pulmonary embolism; Recurrent miscarriage; Repetitive strain injury; Scoliosis; Seasonal affective disorder; Squint; Systemic lupus erythematosus; Testicular cancer; Varicocele; Viral meningitis; Vitiligo However, we are always looking for others, so do not let this list discourage you.

Being a contributor involves:

- Appraising the results of literature searches (performed by our Information Specialists) to identify high quality evidence for inclusion in the journal.

- Writing to a highly structured template (about 2000-3000 words), using evidence from selected studies, within 6-8 weeks of receiving the literature search results.

- Working with Clinical Evidence Editors to ensure that the text meets rigorous epidemiological and style standards.

- Updating the text every eight months to incorporate new evidence.

- Expanding the topic to include new questions once every 12-18 months.

If you would like to become a contributor for Clinical Evidence or require more information about what this involves please send your contact details and a copy of your CV, clearly stating the clinical area you are interested in, to Claire Folkes (cfolkes@bmigroup.com).

\section{Call for peer reviewers}

Clinical Evidence also needs to recruit a number of new peer reviewers specifically with an interest in the clinical areas stated above, and also others related to general practice. Peer reviewers are health care professionals or epidemiologists with experience in evidence based medicine. As a peer reviewer you would be asked for your views on the clinical relevance, validity, and accessibility of specific topics within the journal, and their usefulness to the intended audience (international generalists and health care professionals, possibly with limited statistical knowledge). Topics are usually 2000-3000 words in length and we would ask you to review between 2-5 topics per year. The peer review process takes place throughout the year, and our turnaround time for each review is ideally 10-14 days.

If you are interested in becoming a peer reviewer for Clinical Evidence, please complete the peer review questionnaire at www.clinicalevidence.com or contact Claire Folkes(cfolkes@bmigroup.com). 